\title{
Studi Efisiensi Proses Pengeringan Rengginang Pada Alat Pengering Yang Memiliki Delapan Loyang
}

\author{
Rengginang Drying Process Efficiency Study On 8 Pans Dryer Machine \\ Deny Suryana, Ardhaningtyas Riza Utami, Arif Indro Sultoni, Hadid Tunas Bangsawan \\ Baristand Industri Surabaya \\ Surabaya, Indonesia \\ denysuryana.81@gmail.com
}

\begin{abstract}
Abstrak - Pada penelitian ini dilakukan desain dan pengujian efisiensi oven pengeringan pada rengginang basah yang memiliki delapan tingkat loyang terbuat dari bahan stainless steel, ukuran wadah atau loyang raknya dengan panjang / lebar $50 \mathrm{~cm}$ dan tingginya $5 \mathrm{~cm}$. Pada tungku pembakaran dilengkapi pipa kisi - kisi dengan diameter 1,5inchi dengan jumlah 8 buah. Yang perlu dicatat pada proses pengeringan ini adalah temperatur ruang pengering dan udara luar, lama waktu pengeringan, konsumsi bahan bakar LPG yang digunakan, serta kadar air terkandung dalam rengginang, baik sebelum maupun setelah dikeringkan.Agar pemanasan rengginang merata dan tidak terjadi gosong. Pelaksanaan pemindahan rengginang berturut-turut dimulai dari tingkat terbawah sampai teratas. Selama proses pengeringan, temperatur udara pengering dicatat setiap memulai pengeringan dan terakhir pengeringan menggunakan indicator pada oven. Perhitungan kadar air rengginang, menggunakan acuan SNI 01-4307-1996. Hasil prototype oven dengan kapasitas pengeringan rengginang sekitar 392Pcs, menggunakan bahan bakar LPG. Selama proses pengeringan dilakukan pengaturan pada kompor gas bahan bakar LPG agar temperatur ruang pengering berkisar antara $40^{\circ} \mathrm{C}$ sampai $60^{\circ} \mathrm{C}$ selama 1 jam pertama untuk mencapai suhu stabil. Pemindahan rengginang ke delapan loyang berbeda dilaksanakan setiap 45menit, Lama pengeringan rengginang dengan jumlah 392pes, selama 3 jam 30 menit, hingga terjadi penurunan kadar air dari 51,41 \% menjadi 12,33\%. Data yang diperoleh pada penelitian ini, selanjutnya digunakan sebagai dasar perhitungan efisiensi termal pengeringan rengginang tersebut, yaitu sebesar $30,80 \%$.
\end{abstract}

Kata kunci : rengginang, kadar air, SNI 01-4307-1996

Abstract - In this research, the design and testing of the efficiency of a drying oven for wet rengginang which has eight levels of stainless steel pan was carried out, the size of the container or the rack with a length / width of $50 \mathrm{~cm}$ and a height of $5 \mathrm{~cm}$. The furnace is equipped with a pipe with a diameter of 1.5 inches with total of 8 pieces. Noteworthy in this drying process are the drying chamber temperature and outside air, the drying time, the consumption of LPG fuel used, as well as the water content contained in rengginang, both before and after drying. In order to distribute heating evenly and to avoid burnt on rengginang. Rengginang sequentially placed in a row starting from the lowest level to the top. During the drying process, the temperature of the drying air is recorded at the start of drying and at end of drying using the temperature indicator on the oven. Rengginang water content is calculated using SNI 01-4307-1996 as reference. The results of the prototype oven with drying capacity around 392Pcs, using LPG fuel. During the drying process an adjustment is made on the LPG fuel gas stove so that the drying chamber temperature ranges from $40^{\circ} \mathrm{C}$ to $60^{\circ} \mathrm{C}$ during the first hour to reach a stable temperature. The sequentially placed of rengginang to eight different baking sheets is carried out every 45 minutes, the duration of drying rengginang with an amount of 392pcs, for 3 hours 30 minutes, until there is a decrease in water content from $51.41 \%$ to $12.33 \%$. The data obtained in this research then used as a basis for calculating the thermal efficiency of the rengginang drying, which is $30.80 \%$.

Keywords : rengginang, SNI 01-4307-1996

\section{PENDAHULUAN}

Rengginang Lorjuk Merupakan salah satu jenis RENGGINANG yang terkenal, camilan asal madura kabupaten sumenep ini memiliki keistimewaan dengan taburan lorjuk. Di sumenep camilan rengginang ini terletak di desa prenduan kecamatan pragaan pada koperasi lokrepot. Tingginya permintaan rengginang pada masyarakat Indonesia, produsen tidak mampu mencukupi permintaan pasar.

Dalam 1 bulan lebih dari 10000 buah rengginang lorjuk di ekspor ke luar madura untuk di distribusikan kepada seluruh pedagang atau konsumen di beragam daerah data dari BPS kota sumenep 2018. [1];[2]

Tingginya permintaan pada produk tersebut belum di diimbangi dengan teknologi pengolahan rengginang (khususnya pada proses penjemuran). Saat ini produksi pada koperasi tersebut kapasitasnya sangat rendah rata - rata produksinya perharinya kurang lebih 50-175 rengginang dengan total lama waktu produksi sampai dengan proses penjemuran membutuhkan waktu 4-7 hari.[3] Pada proses penjemurannya yang masih mengandalkan sinar matahari, sehingga ketergantungan pada kondisi iklim saat pengeringan menjadikan persoalan tersendiri. Apalagi dimusim penghujan antara bulan Nopember sampai dengan Mei bisa mempengaruhi penurunan produksi sampai dengan 
60\%. [4] Ini mengakibatkan tidak bisa mengoptimalkan kapasitas produksi, karena proses pengeringan yang masih tergantung pada intensitas cahaya matahari dan memerlukan tempat yang sangat luas.

Dari hasil observasi dan diskusi lamanya proses penjemuran ini mempengaruhi kapasitas produksi, estimasi penjemuran antara $\pm 1-4$ hari dengan kondisi tidak hujan dan bila terjadi hujan lama penjemuran \pm 4-6 hari dari total produksi dalam $1 \mathrm{x}$ penjemuran rengginang antara \pm 700 pcs. [5] Seperti pada gambar 1 proses pengeringan rengginang yang masih meggunakan sinar matahari.

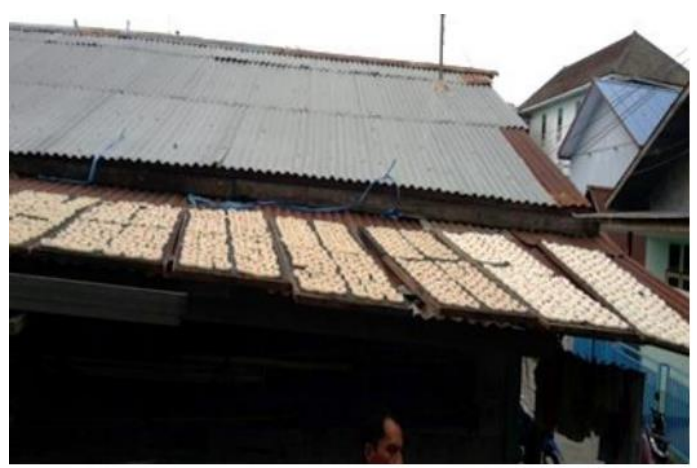

Gambar 1. Proses Pengeringan Rengginang

Apabila pengeringan rengginang dilakukan menggunakan mesin pengering, udara digunakan sebagai media pemanas, caranya udara tersebut dialirkan di dalam pipa-pipa, yang dipanaskan oleh gas selanjutnya udara panas yang dihasilkan dialirkan menggunakan blower, menuju ke dalam ruang oven rengginang. Dengan cara demikian, untuk menurunkan kadar air rengginang menjadi sebesar 8-12\% membutuhkan waktu sekitar 3-7 jam. Sesuai dengan persyaratan SNI 01-4307-1996 batasan maksimal kadar air sebesar $12 \%$. [6]

Sebelumnya pernah di bahas mengenai pengeringan adonan roti donat dengan kapasitas oven $20 \mathrm{~kg}$ (basah), dikeringkan menjadi seekitar $11 \mathrm{~kg}$ diperlukan LPG sebanyak $7,6 \mathrm{~kg}$ dari tingkat kekeringan semula $76,11 \%$ menjadi $26,87 \%$. Waktu yang diperlukan 6 jam 30 menit. Untuk temperatur ruangaan pengering oven sekitar $49^{\circ} \mathrm{C}$. [7]

Maka pada penelitian ini kami mencoba membuat oven rengginang dengan desain tungku pembakaran dan oven terpisah. Hasil dari prototype tersebut di lakukan unjuk kerja untuk mengetahui efisiensi pengeringan rengginang dengan kapasitas maksimal $\pm 15 \mathrm{~kg}$ atau 392 pcs dengan delapan tingkat tray (8 loyang) menggunakan bahan bakar LPG. Dengan rancangan ini harapannya adalah dapat memanfaatkan maksimal mungkin kalor hasil pembakaran bahan bakar LPG (liquifuid petroleum gas) dan meningkatkan kapasitas produksi perhari $20 \%$.

Adapun untuk mengetahui efisiensi pada alat pengering tersebut, melalui perhitungan secara sebagai berikut [7]:
Kalor untuk pemanasan rengginang basah $Q_{D}$, terdiri dari beberapa komponen energy dan dinyatakan sebagai [6] :

$Q_{D}=Q_{C}+Q_{W}+Q_{E W}$ dengan,

$Q_{C}=$ kalor pemanasan rengginang (k Joule)

$Q_{W}=$ kalor pemasan air yang terkandung pada rengginang (k Joule)

$Q_{\text {ew }}=$ kalor penguapan air rengginang (k Joule)

Kalor pemanasan rengginang, $Q_{C}$ dinyatakan dengan persamaan berikut :

$Q_{C}=W_{C f C P C}\left(T_{D-} T_{F}\right)$

$W_{C f}=$ berat rengginang basah setelah produksi $(\mathrm{KG})$

${ }_{C P C}=$ panas jenis rengginang $\left(\mathrm{k} \mathrm{Joule} / \mathrm{kg} .{ }^{0} \mathrm{C}\right)$

$T_{D}=$ temperature rengginang kering $\left({ }^{0} \mathrm{C}\right)$

$T_{F}=$ temperature rengginang awal (basah) $\left({ }^{0} \mathrm{C}\right)$

Kalor pemanasan air rengginang, $Q_{W}$ dinyatakan dengan persamaan berikut :

$Q_{W}=W_{W f C P W}\left(T_{D-} T_{F}\right)$

$W_{W f}=$ Berat kandungan air pada rengginang $(\mathrm{KG})$

${ }_{C P W}=$ Panas jenis air $\left(\mathrm{k}\right.$ Joule $\left./ \mathrm{KG} .{ }^{0} \mathrm{C}\right)$

Kalor penguapan air rengginang,

$Q_{E W}=\Delta W_{W} h_{f g}$

Dengan

$\Delta W_{W}=$ berat air yang terbuang selama pengeringa, $\mathrm{kg}$

$$
=W_{W f}-W_{W e}
$$

$W_{W e} \quad=$ berat air dalam regginang saat akhir (setelah pengeringan), $\mathrm{kg}$

$h_{f g} \quad=$ kalor laten penguapan $(\mathrm{k}$ joule $/ \mathrm{kg})$

Efisiensi termal alat pengering rengginang, ditentukan sebagai berikut :

$\eta=\frac{Q D}{Q B} 100 \%$

dengan

$\mathrm{QB}=$ Kalor hasil pembakaran bahan bakar LPG (kJoule)

\section{BAHAN DAN METODE}

\section{Metode}

Kapasitas produksi antara 600-1000 pcs perhari, dimensi rengginang yaitu tinggi $3 \mathrm{~cm}$ dan diameter $5 \mathrm{~cm}$ maka desain oven yang kami buat dengan biaya yang terjangkau kira - kira dapat menampung sekitar \pm 392 pcs rengginang, maka spesifikasi oven mempunyai dimensi panjang $83 \mathrm{~cm}$ dan tinggi $89 \mathrm{~cm}$ dan menggunakan bahan besi stainless steel. Jumlah rak atau loyang yang digunakan sebanyak 8 rak. Ukuran loyang atau rak panjang nya sekitar $50 \mathrm{~cm}$, lebar nya $50 \mathrm{~cm}$ dan tinggi nya $5 \mathrm{~cm}$ jarak antar Loyang $\pm 8 \mathrm{~cm}$.

Sebelum dilakukan proses pengeringan rengginang, mesin oven rengginang dilakukan uji coba alat tanpa rengginang (beban) dengan suhu awal ruangan pengeringan 
sekitar $\pm 27^{\circ} \mathrm{C}$ dan dilakukan setting/pengaturan suhu pada $60^{\circ} \mathrm{C}$, untuk mencapai suhu tersebut diperlukan waktu sekitar 15 menit sampai 20 menit. Hasil uji coba pada oven tersebut suhu stabil pada range antara $55^{\circ} \mathrm{C}-57^{\circ} \mathrm{C}$ dan memerlukan konsumsi bahan bakar LPG seberat sekitar $0,10 \mathrm{~kg}$. setelah dicapai suhu tersebut, dilanjutkan proses pengeringan dengan memasukan beban rengginang basah pada 8 loyang terisi penuh sekitar $15 \mathrm{~kg}$ atau 392pcs. Bahan yang dikeringkan adalah rengginang masih basah setelah di kukus yang masih terdapat kadar airnya sekitar 51,40\%. Rengginang yang basah akan dipanaskan pada loyang oven secara merata, selanjutnyan dilakukan proses pengeringan. Setelah proses pengeringan dilakukan beberapa jam, maka rengginang terkering yang berada pada loyaang tingkat satu (atas) dapat diambil. Selanjutnya secara berurutan dari rengginang yang berada pada loyang / tingkat ke dua sampai loyang ke delapan dipindahkan ke satu tingkat diatasnya. Hal ini dimaksudkan agar tingkat kekeringan dan kematangan pada rengginang merata dan tidak mengalami gosong.

Aktuator / pengendali suhu pada suatu ruangan atau alat bisa dilakukan dengan dua metode yaitu sistem kendali On dan sistem kendali Off. Pengendali suhu ruangan dengan menggunakan sistem kendali thermocontrol terdapat mekanisme pengecekan suhu di dalam oven yaitu dengan menggunakan sensor suhu. Untuk sebuah sistem kendali suhu ruangan metode on / off pada blower berbasis thermocontrol, sensor akan mengukur suhu aktual di dalam ruangan oven dan kemudian mengirimkan hasil pengukurannya ke thermocontrol. Thermocontrol selanjutnya akan membandingkan suhu yang diinginkan dengan suhu aktual hasil pengukuran oleh sensor.

Hasil perbandingan suhu antara nilai masukan (yang diinginkan) dengan nilai aktualnya inilah yang akan digunakan oleh thermocontrol ini apakah akan menghidupkan atau mematikan blower atau kipas yang ada di ruang tungku pembakaran.

Diagram blok sistem pengendali suhu oven dengan menggunakan metodes sistem kendali on / off berbasis thermocontrol dapat dilihat pada Gambar 1.

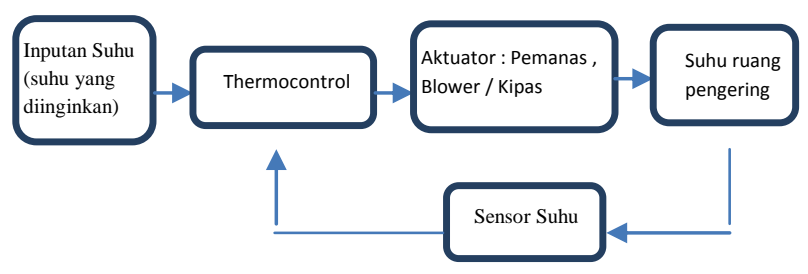

Gambar 1. Diagram blok sistem pengendali suhu
Bahan-bahan yang digunakan pada mesin oven antara lain :

$>$ Thermocontrol digital

$>$ Termokopel (sensor panas)

$>$ Blower

Plat Stainles Steel

\section{HASIL DAN PEMBAHASAN}

Telah dibuat oven pengering rengginang dengan sistem tungku pembakaran dan oven terpisah seperti pada gambar Gambar 2.

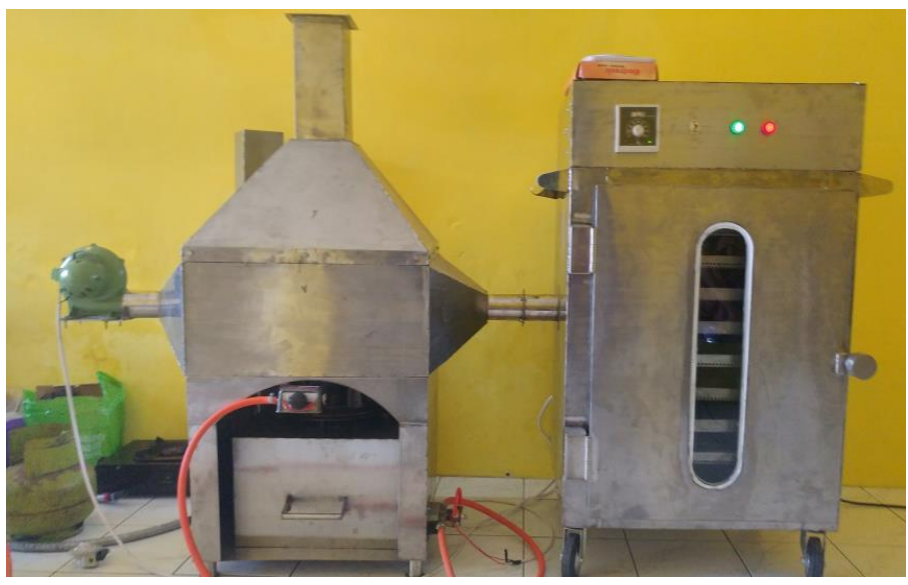

Gambar 2 Mesin pengering rengginang tersusun delapan loyang

Untuk kapasitas pengeringan rengginang seberat $\pm 15 \mathrm{~kg}$ ini, kondisi udara lingkungan saat dilakukan pengambilan data menunjukan bahwa suhu ambient sekitar $30^{\circ} \mathrm{C}$. Dari hasil perhitungan menunjukan bahwa, untuk pengeringan rengginang basah dengan kapasitas oven $15 \mathrm{~kg}$, laju penurunan tingkat kekeringan setiap jam sebesar 13,03\% dengan estimasi lama waktu pengeringan 3 jam.

Untuk pengeringan rengginang kapasitas tersebut, kalor yag diperlukan untuk pemanasan rengginang sebesar 14236,74741 kilo Joule, kalor yang diperlukan untuk pemanasan kandungan dari temperatur $27^{\circ} \mathrm{C}$ sampai temperatur pengeringan adalah 14,392 kilo Joule sebesar dan kalor untuk penguapan air yang terkandung didalamya sebesar 886,608Joule. Jadi dapat diketahui hasil kebutuhan energi selama proses pengeringan renginang basah adalah sebesar 15137,74741kilo Joule. Waktu yang diperlukan pada proses rengginang tersebut adalah sebesar 3jam 30 menit, suhu stabil setelah 1 jam pertama. Maka kebutuhan energy yang dibutuhkan pada proses pengeringan tiap detiknya atau dayanya adalah sebesar $3,9 \mathrm{~kW}$. 
Sedangkan kalor hasil pembakaran bahan bakar elpiji adalah sebesar 15137,21 kilo Joule, maka efisiensi termal alat pengering adalah sebesar $30,80 \%$

\section{KESIMPULAN}

Dari percobaan yang dilakukan pada perekayasaaan dalam pembuatan oven dengan menggunakan bahan bakar lpg dan sabut kelapa, dapat disimpulkan untuk proses pengeringan rengginang basah dengan kapasitas oven $15 \mathrm{~kg}$ dibutuhkan bahan bakar gas lpg sebanyak $0,10 \mathrm{~kg}$ dengan lama waktu 3 jam 30 dan menggunakan bahan bakar sabut kelapa dibutuhkan $10 \mathrm{~kg}$ sabut kelapa dengan lama waktu 3 jam 20 menit. Hasil pengovenan pada rengginang kadar air yang diperoleh dibawah batas maksimal SNI 12\%, yaitu $11,15 \%$ untuk bahan bakar sabut kelapa dan 11,30\% untuk bahan bakar lpg. Berdasarkan lama waktu dan nilai akhir kadar air pada rengginang diperoleh efisiensi oven pengering menggunakan bahan bakar LPG sebesar 30,80\% lebih tinggi dibandingkan dengan sabut kelapa yaitu 13,35\%

\section{DAFTAR PUSTAKA}

[1] P. Silalahi, "OVEN PENGERING MAKANAN RINGAN SERBA GUNA," J. Tek. Elektro Vol. 2, No. 1, Januari 2015, pp. 1-4, 2015.

[2] Seksi Neraca Wilayah dan Analisis Statistik, "Statistik Daerah Kab . Sumenep," in BPS Kabupaten Sumenep, 2018, pp. 1-48.

[3] felix eko wismo susanto johanes, “JILID II Kluster
Sain dan Teknologi," Pros. Semin. Nas. Teknol. Terap. SV UGM 2017, no. ISBN 978-602-1159-279, pp. 373-378, 2017.

[4] P. Usaha, K. Khas, and M. Berbahan, "PADA AGROINDUSTRI KREPEK TETTE DI PAMEKASAN Agriekonomika , ISSN 2301-9948," vol. 2, pp. 40-48, 2013.

[5] N. Maria Naibaho et al., "Pemanfaatan Teknologi Tepat Guna Dalam Meningkatkan Produksi Rengginang Di Kelurahan Sidodadi Kota Samarinda," JIPEMAS J. Inov. Has. Pengabdi. Masy., vol. 3, no. 1, p. 23, 2019, doi: 10.33474/jipemas.v3i1.4465.

[6] S. N. Indonesia and B. S. Nasional, "Kerupuk beras," 1996.

[7] NESYA TRESIA, "PENGARUH SUHU OVEN DALAM PEMANGGANGAN TERHADAP KUALITAS KUE SUS," no. 6, pp. 67-72, 2017.

[8] S. Mochamad Ivan Fadli, Hamasda Miftachul Alfa'izin, "perancangan alat teknologi tepat guna mesin pengering roti," J. Tek. Elektro Vol. 2, No. 1, Januari 2014, vol. Volume 2, pp. 1-9, 2014.

[9] H. Supriyono and S. Ariwibowo, "RANCANGBANGUN PENGERING PANILI OTOMATIS BERBASIS MIKROKONTROLER," Simp. Nas. RAPI XIV - 2015 FT UMS, vol. ISSN 1412-, pp. 50-56, 2015.

[10] F. Edition, “

Modern_Control_Engineering_K_Ogata_ 5Th_Edition," vol. 4, no. 3.pp. 419-419, 1970. 